\title{
HISTÓRIA ORAL COMO MÉTODO PARA A COMPREENSÃO DO OFÍCIO DAS PARTEIRAS DO SEMIÁRIDO BRASILEIRO ${ }^{1}$
}

\author{
Samara Calixto Gomes², Jaqueline Alves Silva, Dayanne Rakelly de Oliveira4, Maria de Fátima Antero Sousa \\ Machado ${ }^{5}$, Ana Karina Bezerra Pinheiro ${ }^{6}$, Glauberto da Silva Quirino ${ }^{7}$
}

${ }^{1}$ Extraído da dissertação - “Quem faz parto é a natureza”: Memórias de parteiras do Cariri, Ceará, apresentada ao Programa de Pós-Graduação em Enfermagem da Universidade Regional do Cariri (URCA). Crato, Ceará, Brasil, em 2016.

${ }^{2}$ Mestre em Enfermagem. Docente do Departamento de Enfermagem da URCA, Unidade Descentralizada de Iguatu (UDI). Iguatu, Ceará, Brasil. E-mail: samaracalixto@hotmail.com

${ }^{3}$ Acadêmica do Curso de Graduação em Enfermagem da URCA. Crato, CE, Brasil. E-mail: jekylane@hotmail.com

${ }^{4}$ Doutora em Bioquímica Toxicológica. Professora do Departamento de Enfermagem e do Programa de Pós-Graduação em Enfermagem da URCA. Crato, CE, Brasil. E-mail: dayanne_rakelly@yahoo.com.br

${ }^{5}$ Doutora em Enfermagem. Professora do Departamento de Enfermagem e do Programa de Pós-Graduação em Enfermagem da URCA. Crato, CE, Brasil. E-mail: fatimaantero@uol.com.br

${ }^{6}$ Doutora em Enfermagem. Professora do Programa de Pós-Graduação em Enfermagem da Universidade Federal do Ceará. Fortaleza, CE, Brasil. E-mail: anakarinaufc@hotmail.com

${ }^{7}$ Doutor em Educação em Ciências. Professor do Departamento de Enfermagem e do Programa de Pós-Graduação em Enfermagem da URCA. Crato, CE, Brasil. E-mail: glauberto.quirino@urca.br

\section{RESUMO}

Objetivo: compreender o processo histórico do ofício das parteiras do semiárido nordestino brasileiro por meio da história oral.

Método: estudo qualitativo realizado em nove municípios do Cariri cearense com 16 parteiras, por meio do método da história oral. Foi utilizada, como instrumento de coleta de dados, a entrevista semiestruturada, com gravação das entrevistas em vídeo. Os relatos foram transcritos, textualizados e transcriados, sendo analisados segundo o método da história oral de vida.

Resultados: a inserção de mulheres no ofício de parteiras ocorreu de forma transcendental ou essencial. Foi considerado um dom autônomo, divino ou aprendido pelo convívio com outras parteiras mais experientes. Seus conhecimentos variaram entre os saberes empírico e científico, tendo sido modificados ao longo do tempo, por conta do crescimento da medicalização, instigando a reflexão diante da atuação profissional voltada à saúde da mulher. Isto valorizou o parto, tornado um momento único, respeitando todos seus significados e devolvendo à mulher seu direito de ser mãe com humanidade e segurança.

Conclusão: ficou evidente a forma natural e transcendental com que as parteiras foram inseridas neste ofício, motivadas pelo sentimento de altruísmo em um contexto histórico e social de ausência de acesso universal à saúde, de localização geográfica rural e de pouca disponibilidade de recursos humanos na saúde. Ficaram evidentes, deste modo, seus valores e sua importância no cenário da saúde obstétrica brasileira.

DESCRITORES: Parteira leiga. Enfermagem obstétrica. Saúde da mulher. Cultura. Memória. Traços de história de vida.

\section{THE ORAL HISTORY AS A METHOD FOR UNDERSTANDING THE BRAZILIAN SEMI-ARID MIDWIVES' JOB ${ }^{1}$}

\begin{abstract}
Objective: to understand the historical process of the midwives' job in the Brazilian Northeastern semi-arid region through the oral history. Method: qualitative study carried out in nine municipalities of Cariri, in Ceará, with 16 midwives, using the oral history method. The semistructured interview was used as a data collection instrument, with video interviews recorded.. The reports were transcribed, textualized and transcreated, being analyzed according to the oral life history method.

Results: the insertion of women working as midwives took place in a transcendental or essential way. It was considered an autonomous gift, divine or learned by living with other more experienced midwives. Their knowledge varied between the empirical and scientific knowledge, having been modified over time, due to the growth of the medicalization, instigating the reflection due to the professional action focused on women's health. This valued the childbirth, making it a unique moment, respecting all its meanings and giving back to the woman her right to be a mother with humanity and security.

Conclusion: it was evident the natural and transcendental way in which the midwives were inserted in this role, motivated by the feeling of altruism in a historical and social context of absence to universal access to health, rural geographic location and little availability of human resources in health. Thus, their values and their importance in the Brazilian obstetric health scenario were evident.
\end{abstract}

DESCRIPTORS: Lay midwife. Obstetric nursing. Women's health. Culture. Memory. Life history traits. 


\section{HISTORIA ORAL COMO MÉTODO PARA LA COMPRENSIÓN DEL OFICIO DE LAS PARTEIRAS DEL SEMIÁRIDO BRASILEÑO}

\section{RESUMEN}

Objetivo: comprender el proceso histórico del oficio de las parteras del semiárido nordestino brasileño por medio de la historia oral.

Método: estudio cualitativo realizado en nueve municipios del Cariri cearense con 16 parteras, por medio del método de la historia oral. Se utilizó, como instrumento de recolección de datos, la entrevista semiestructurada, con grabación de las entrevistas en video. Los relatos fueron transcritos, textualizados y transcribados, siendo analizados según el método de la historia oral de vida.

Resultados: la inserción de mujeres en el oficio de parteras ocurrió de forma trascendental o esencial. Fue considerado un don autónomo, divino o aprendido por la convivencia con otras parteras más experimentadas. Sus conocimientos variaron entre los saberes empírico y científico, habiendo sido modificados a lo largo del tiempo, por el crecimiento de la medicalización, instigando la reflexión ante la actuación profesional orientada a la salud de la mujer. Esto valoró el parto, convertido en un momento único, respetando todos sus significados y devolviendo a la mujer su derecho de ser madre con humanidad y seguridad.

Conclusión: quedó evidente la forma natural y trascendental con que las parteras fueron insertadas en este oficio, motivadas por el sentimiento de altruismo en un contexto histórico y social de ausencia de acceso universal a la salud, de localización geográfica rural y de poca disponibilidad de recursos humanos en la salud. Se quedaron evidentes, de este modo, sus valores y su importancia en el escenario de la salud obstétrica brasileña.

DESCRIPTORES: Partería laica. Enfermería obstétrica. Salud de la mujer. Cultura. Memoria. Rasgos de la Historia de vida.

\section{INTRODUÇÃO}

A experiência materna é um evento importante na vida das mulheres, sendo marcada pela transformação de seu papel social. ${ }^{1}$ Em algumas regiões do Brasil, o auxílio obstétrico era fornecido por mulheres da própria comunidade e a técnica utilizada era adquirida por meio do acúmulo de saberes sobre a parturição. Então, aquela mulher que a comunidade considerava como a mais experiente era reconhecida como parteira, que, com o tempo, transformou seu dom em profissão, fazendo da experiência a sua competência. ${ }^{2-3}$

A Região Nordeste do Brasil tem predominância de clima semiárido, altas temperaturas, baixas precipitações pluviométricas e que abriga a população mais pobre do país. ${ }^{4}$ Além da assistência ao parto, as parteiras prestavam cuidados domiciliares à puérpera e ao recém-nascido. Também chamadas de "aparadeiras", "comadres" ou "parteiras leigas", estas mulheres são dotadas de saber popular - muitas vezes, decorrente de lendas e crendices sobre a gestação, associadas à natureza. ${ }^{5}$ Elas tornaram-se responsáveis pelo auxílio, acolhimento e cuidado à mulher durante o ciclo gravídico-puerperal e ao recém-nascido, com base em conhecimentos orais e gestuais experimentados e transmitidos entre as gerações. ${ }^{2-7}$

No Ceará, Estado nordestino brasileiro, as parteiras também são conhecidas como "cachimbeiras", em decorrência de um dos principais rituais realizados durante o trabalho de parto. A parteira, após fumar o cachimbo, cuspia em suas mãos e, em seguida, passava no abdome da mulher, acreditando que, assim, acelerava o nascimento da criança. Após o banho do recém-nascido, tragava a fumaça e soprava no umbigo da criança, antes de cobri-lo. Afirmavam que, desta maneira, apressariam a queda do coto umbilical. ${ }^{8}$

Neste contexto, questiona-se: quais as trajetórias e vivências históricas do ofício das parteiras do semiárido nordestino brasileiro? Ao realizar este estudo, faz-se um resgate de suas memórias, seus valores, suas técnicas e seus rituais que configuram um ethos no cuidado obstétrico, ou seja, o que se considera importante para o conhecimento do presente e de si, produzindo uma reflexão que oriente as práticas obstétricas no futuro.

Para responder à questão anterior, faz-se necessária a realização de um estudo conduzido por um referencial metodológico oriundo da história social: a história oral. Tal método justifica-se por possibilitar acessar as memórias e os simbolismos das parteiras, bem como, por privilegiar o estudo das representações e atribuir um papel central às relações entre memória e história, buscando realizar uma discussão mais refinada das práticas e acontecimentos do passado. ${ }^{9}$

Este estudo objetivou compreender o processo histórico do ofício das parteiras do semiárido nordestino brasileiro por meio da história oral.

\section{MÉTODO}

Estudo qualitativo, no qual utilizou-se o método da história oral, que é conceituada como método e prática de apreensão de narrativas de testemunhas, capaz de promover análise de processos sociais. ${ }^{10}$

Para a aplicação da história oral, é necessária a compreensão de três conceitos que hierarquizam os estágios deste método: comunidade de destino, 
colônia e redes. Chama-se comunidade de destino um determinado cenário, em que grupos compartilham os mesmos comportamentos e possuem como marca uma memória coletiva. ${ }^{10}$ Assim, denominou-se comunidade de destino as parteiras leigas ou "cachimbeiras" da região do Cariri cearense no semiárido brasileiro.

Colônia é definida por padrões gerais de uma parcela de pessoas que compõem uma mesma comunidade de destino. Trata-se de uma fração do todo, em que um grupo de pessoas compartilha interesses, motivos ou outras características afins. ${ }^{10}$ Para o estudo, o grupo de maior interesse foram as parteiras leigas ou "cachimbeiras", ou seja, mulheres dotadas de conhecimentos populares, residentes em municípios da região do Cariri cearense e que tivessem atuado como parteira nestes locais. ${ }^{3}$

Foram critérios de exclusão estar impossibilitada de colaborar com a pesquisa de forma verbal ou não apresentar auto e alo orientação preservada.

As parteiras foram contatadas e captadas por meio de visitas dos pesquisadores na zona rural dos municípios pertencentes à colônia. Nesta ocasião, os residentes locais eram indagados sobre a existência de parteira na região. Esta primeira parteira indicada por eles era considerada o ponto zero.

Iniciou-se a coleta de dados, com auxílio do ponto zero e, a partir dele, construiu-se a rede. A rede é uma subdivisão da colônia, na qual podem-se criar parâmetros individuais para que sirvam de critérios de escolha das entrevistadas. Ela sempre tem início no ponto zero, que foi a primeira entrevistada. A partir dela, uma segunda era indicada, que, por sua vez, indicou uma terceira e, assim, cria-se uma rede de entrevistas. ${ }^{10}$

Neste estudo, as redes foram definidas de acordo com as cidades visitadas, totalizando 16 entrevistadas em nove municípios da colônia. Este número de entrevistadas correspondeu à totalidade de parteiras localizadas nos municípios de Abaiara, Barbalha, Caririaçu, Crato, Farias Brito, Jardim, Juazeiro do Norte, Missão Velha e Várzea Alegre. Cada município teve a sua rede composta a partir da primeira entrevistada. O período de coleta de dados ocorreu de julho a dezembro de 2015.

Adotou-se como instrumento de coleta de dados a entrevista semiestruturada, que foi gravada em vídeo e realizada nas residências das parteiras, em acordo com a disponibilidade de cada uma, mediante assinatura do termo de autorização de uso e cessão de direito de exibição de imagem e do Termo de Consentimento Livre e Esclarecido (TCLE). As participantes analfabetas apuseram sua impressão datiloscópica. Após o início da conversa informal, foi utilizado um roteiro prévio, com questões que envolviam dados de identificação da participante. A entrevista foi direcionada pela questão norteadora: "como a senhora chegou a ser parteira?".

Com os depoimentos coletados, os vídeos foram analisados e os relatos transcritos. A textualização aconteceu com a transformação destes escritos em uma narração e, por fim, foi feita a transcriação, na qual houve a recriação do texto, ordenando parágrafos, retirando ou acrescentando palavras e frases, tornando-se possível a elaboração de um memorial sobre as suas histórias de vida, contadas por elas mesmas. ${ }^{10}$

Após a transcriação, iniciou-se a análise dos dados, sendo utilizado o método da história oral de vida. ${ }^{10}$ Uma pesquisa baseada neste método oferece suporte metodológico nos estudos relacionados às memórias e narrativas orais de história de vida.

Os dados empíricos foram avaliados quanto à coerência interna com a leitura, como um todo buscando supressões, contradições, incoerências e anacronismos. Para tanto, as evidências foram colocadas dentro de um contexto mais amplo, considerando o viés da seleção do grupo. ${ }^{11}$

Em relação às questões éticas da pesquisa, esta foi desenvolvida em acordo com a Resolução 466/12, do Conselho Nacional de Saúde, que aborda as pesquisas envolvendo seres humanos. A pesquisa foi submetida ao Comitê de Ética em Pesquisa (CEP) da Universidade Regional do Cariri (URCA), sendo aprovada por meio do parecer de número $974.849 \mathrm{e}$ CAAE 42109615.2.0000.5055. As parteiras foram identificadas pela letra $\mathrm{P}$, seguida do numeral cardinal de sequência da entrevista.

\section{RESULTADOS}

Durante as entrevistas, foi prevalente a assertiva de que a inserção de mulheres no ofício de parteiras ocorreu de forma transcendental ou essencial. Assim, era considerado um dom autônomo, divino ou aprendido por meio do convívio com outras parteiras mais experientes.

\section{Deus me deu esse dom}

Por diversas vezes, as parteiras consideraram o seu trabalho como algo divino, concedido por Deus, que as capacitou para tal ofício. Algumas eram analfabetas, e as demais possuíam baixa escolaridade, situações justificadas pela dificuldade de acesso à escola ou em decorrência das ocupações agrícolas. 
Outras afirmaram ter assistido apenas seus próprios partos e, por meio do conhecimento empírico que provinha da observação, desenvolveram a prática do partejar; para estas parteiras, seus dons surgiram de forma natural e intrínseca. Suas técnicas e rituais descritas eram semelhantes. Era um dom. Parece que foi mandado por Deus (P. 01). Não aprendi com ninguém. Jesus que me deu. Eu tinha aquele trabalho, tão bonito pra Deus como foi! Mas graças à Ele nunca morreu nenhuma nas minha mão (P 08). Em tudo que Deus me deu, aquele dom de eu ser [...] uma rezadeira, ele me deu também de ser uma parteira! [...] Foi o meu dom mesmo! (P 16) Inteligência minha mesmo [...] Deus que me protegia. Eu fazia rapidinho [...] Só na experiência que eu tenho! Aqui é de nascença, minha filha! (P 14)

\section{Era o jeito... Não era de deixar morrer}

A média de idade das parteiras entrevistadas estava em torno dos 75 anos. Pelos relatos, iniciaram seus trabalhos ainda no início da fase adulta, por volta dos 20 anos, nas décadas de 1950 e 1960. Elas se inseriram no ofício de parteiras dentro de um contexto histórico brasileiro, no qual o acesso à saúde não era universal. Sua atuação ocorria em áreas geográficas rurais e elas foram motivadas pelo altruísmo. Eu ia que era o jeito [...] E era difícil as mutheres naquelas gojas (sic)... tinha casa aqui, e outra não sei aonde. Ai, as que eram mais perto, já acudia aquelas que estavam doente. Aí eu chegava lá às vezes, já tinha de agir, que já era quase na última hora. Aí tinha de acudir as coitada. Não era de deixar morrer (P 04) Eu fui forçada pelas circunstâncias, sabe? Forçada! Logo, aqui não tinha nem hospital. Não tinha nenhuma condição de conforto. Os partos eram feitos em casa. Do jeito que Deus queria. Fiz muito parto complicado (P 12) Eu fui morar na Emboscada e lá não tinha parteira, não tinha ninguém! Ai as vizinhas minha, quando ia pra ganhar menino, era eu que ia! [...] dava tudo certo! Elas tão tudo viva, filho tudo vivo, não morreu ninguém! (P 14) Chamava... Eu ia. Fazer o quê? Era de deixar morrer? (P 15)

Destaca-se que as circunstâncias materiais deram um caráter de obrigatoriedade da inserção destas parteiras no ofício, mas existia um sentimento de tristeza pela extinção progressiva de seu trabalho, decorrente do aumento da assistência de profissionais de saúde na atenção ao parto e da mudança de seu cenário para o hospital. Desta forma, exerceram seu papel social com altruísmo, ao promoverem assistência às parturientes, quando as políticas públicas estavam ausentes. Eu não achei mais quem quisesse. Não achei pra quem eu botasse no lugar (sua sucessora) [...] Porque depois que apareceu doutor e enfermeiro e enfermeira, ai não pode mais botar pra ninguém (P 02) Parei de fazer os partos, porque agora as mulher só quer ter nos hospital. Aí foi se acabando nosso trabalho (P 06).

\section{Não escolhi nada disso!}

A vontade de cuidar do próximo foi determinante para a inserção no ofício. Com todas as dificuldades inerentes ao trabalho como parteira, nem todas demonstravam interesse por ele. No entanto, superaram suas inseguranças em troca do cuidado em saúde, que era ofertado a outrem.

Dentre os motivos que as levaram a trabalhar como parteiras, duas justificaram o interesse financeiro, que as levou a buscar conhecimentos para exercer a profissão. Quando fiquei viúva, foi a primeira coisa que comprei foi um tear... para eu tecer rede pra sobreviver com os filhos. Os filhos botavam uma rodinha e eu fui tecer. Mas eu não aguentei devido meus problema no joelho desde desse tempo (P 03) Eu tinha uma amiga que trabalhava nessa maternidade. Só tinha essa. E ela perguntou se eu queria ir trabalhar. E eu disse: 'olhe, eu vivia na casa de um parente. Não tinha condições' [...] Aí eu disse que ia. Aí comprei umas coisinhas, uma toalha, e era no outro dia que ela vinha me buscar. E eu fui morar lá (P 09).

Esta última inseriu-se no serviço de saúde, conseguindo destaque na comunidade em que vivia. Em seus relatos, contou que a remuneração foi fundamental para o sustento de sua família. Outras, prestavam serviço à comunidade sem esperar retorno financeiro. $\mathrm{O}$ pagamento acontecia por meio de agrados. O dom destas profissionais ficou evidenciado quando referiram não ter escolhido esta profissão, enquanto recebiam diversos tipos de convites e chamados para firmarem-se neste trabalho. Aí sabe o que meu marido dizia? Dizia assim: 'tu vai ser parteira'. Eu dizia: 'Deus me livre!' E num foi que foi? (P 03). Porque eu não tinha vocação assim, né? Eu acho que é uma responsabilidade muito grande. Que, pra ser parteira, a gente tem que dar assistência à comunidade e tudo. Não é só no parto. Tem que acompanhar [...] Mas parteira, quando eram vocacionadas mesmo, elas têm mais cuidado do que as enfermeiras [...] Eu não era muito vocacionada, mas eu gostava de aprender as coisas (P 07) Aí quando foi um dia apareceu um cientista, aí ele disse olhando pra minha mão: 'menina você ainda vai ser uma assistente!' Eu disse: 'pelo amor de Deus num diga isso'. Ele disse: 'disse e está dito e vai ser, você vai ver! E a senhora vai ser tão feliz, nunca vai morrer uma mulher nas suas mãos'. Eu disse: 'não, mas eu num queria esse emprego não' (P 08) Eu fiquei com vontade de sumir, sabe? 'não vou de jeito nenhum. Não tenho condições!' (P 12) 
As parteiras do semiárido brasileiro entendiam que a vocação para partejar relacionava-se à capacidade de atenção complexa que o parto exigia, sobretudo por seus riscos de morbimortalidade. Neste sentido, a assistência ao parto iniciava desde o momento no qual a mulher "adoecia", entrando em trabalho de parto, e continuava até os afazeres domésticos no puerpério.

\section{Eu via como era que as mulheres diziam}

As formas de conhecimentos das parteiras variaram entre o saber empírico e o científico. Algumas receberam orientações de suas mães, avós, parentes próximos ou pessoas que as considerassem capacitadas para o ofício. As mulheres que foram parteiras na comunidade há um bom período e por razões individuais precisaram deixar o trabalho, tendo a necessidade de repassar suas funções às mulheres de sua confiança. Aí eu fui e fiquei fazendo [...] Confiava muito nela e ela conversou muito comigo, como era que fazia os parto, e eu comecei a fazer [...] Maria de Lurdes me ensinou tudo (P 01) Foi! Mãe já tinha morrido, mas ela me motivou depois, antes de morrer [...] Não tinha feito parto ainda não. Ela me ensinou antes de morrer! (P 02)

Das entrevistadas, poucas tiveram a oportunidade de receber orientações de outras parteiras, sendo repassadas com a atenção merecida. A maioria destas mulheres aprendeu apenas observando seus próprios partos ou algum trabalho das parteiras de sua comunidade. Eu enfrentei porque via como era que as mulheres diziam (P 06) Naquilo eu via as mulheres ganharem neném. Quando foi com a idade de 16 anos pra cá, aí eu comecei a fazer parto. Nem tinha medo, eu via o jeito que minha avó fazia (P 13)

Entre as parteiras, apenas três relataram conhecimento formal, sistematizado, recebido em instituições de saúde e ensino, onde foram capazes de aprimorar seus dons com o auxílio da ciência. $\mathrm{Na}$ ocasião, aprenderam os cuidados básicos de higiene geral e outros restritos, relacionados à gestante e recém-nascido. Um sobrinho do meu marido, nesse tempo ele andava... assim... conversava com os prefeito... Aífoi, falou pra mim ir fazer um curso no Crato de obstetrícia, pra eu ver se eu me engajava deu ficar recebendo pela prefeitura [...] Não deu certo nada da prefeitura. [...] Aí eu fiz o curso e fui sendo chamada pra fazer os parto daqui (P 03) Eu fiz um curso de aprendiz (P 09) Fiz o curso, mas nunca havia feito um parto sozinha (P 12).

\section{DISCUSSÃO}

O dom é um significante utilizado como capacidade inata, advindo do latim donum, que significa dádiva e mérito. Pode ser considerado um dote natural, aptidão e até mesmo uma habilidade especial para determinada situação ou ação. Na teologia, é considerado uma graça ou bem espiritual proporcionado por Deus. ${ }^{12}$

A semelhança entre suas técnicas e rituais reflete-se sobre o desenvolvimento e compartilhamento dos dons. Os percursos individuais se repetiam, mesmo em áreas geográficas distintas. Assim, ora foram apresentados de forma essencial, ora construídos socialmente e compartilhados em uma herança cultural.

A perspectiva de um dom essencial provém da crença de que os fenômenos do mundo empírico existem porque são reflexos de uma essência interna comum a um determinado grupo social, que os leva a ser da forma que são. Assim, uma essência não muda. ${ }^{13}$ Seu princípio é acreditar que tudo é uma questão natural e intrínseca.

Em contrapartida, para a perspectiva de construção social, o homem não nasce inteligente, mas também não é passivo sob a influência do meio, ou seja, ele se desenvolve de acordo com os estímulos externos, agindo sobre eles para construir e organizar seu próprio conhecimento, de forma cada vez mais elaborada. ${ }^{14}$

As parteiras do semiárido brasileiro reconstruíram e integraram saberes, atuando em um contexto histórico, no qual o acesso aos serviços de saúde não era universal, o que produzia uma demanda social pelos cuidados prestados por estas mulheres, sobretudo nas classes sociais baixas e áreas rurais. Neste sentido, a atenção obstétrica é influenciada pelas mudanças históricas, políticas e epistêmicas ocorridas no mundo, e cada contexto social possui distintos modelos de cuidados obstétricos. No Brasil, o atual modelo ainda produz iniquidades na assistência. ${ }^{15-16}$ Tais iniquidades provocam uma reflexão sobre o modelo de atenção obstétrica, que tem apresentado forte componente tecnológico e pouca ênfase na subjetividade. Assim, a competência técnica tem sido valorizada, em detrimento das dimensões humana e relacional do cuidado de uma pessoa. ${ }^{17}$ Este componente tecnológico, observado no contexto social brasileiro, usado de forma excessiva ou desnecessária, pode representar riscos à saúde da mulher e do recém-nascido. ${ }^{18}$

No entanto, a partir da década de 1990, surge um movimento contra-hegemônico, organizado em favor da humanização do parto e do nascimento, que luta por uma assistência apropriada ao parto e, principalmente, pela eliminação de intervenções desnecessárias. O foco centrado na autonomia femi- 
nina e na implementação de boas práticas obstétricas é uma condição imperativa para a qualidade do cuidado prestado. ${ }^{19}$

A qualificação desta assistência ainda é uma meta a ser alcançada. Esta atenção deve ser centrada na mulher, incentivando-a a participar da tomada de decisões, com práticas menos intervencionistas, baseadas em evidências e humanizada, que são fundamentais para a consecução da qualidade. ${ }^{18-20}$ Isto resulta em uma atitude ética.

A atitude ética, na assistência obstétrica, requer sensibilidade, que merece ser apreendida em conjunto com saberes tanto empíricos quanto científicos. O cuidado obstétrico é um conhecimento que resulta de processo ativo de interpretações e significados sobre o ciclo gravídico-puerperal dentro de um contexto cultural, social e econômico específico. ${ }^{21}$

O cuidado obstétrico é melhor compreendido quanto maior a interação com os diferentes contextos da vida cotidiana social, cultural e espiritual das mulheres. Assim, cuidar de uma parturiente requer conhecimento e respeito de seus saberes, valores e crenças. Neste sentido, a assistência prestada pelas parteiras é capaz de produzir sentimento de segurança e satisfação no processo de parir e nascimento. $^{16-22}$

Nesse sentido, esta assistência articula-se às dimensões individual e social, envolvendo a aplicação de conhecimentos científicos e saberes locais, e considerando as dimensões subjetivas e as representações sociais como uma forma de conhecimento elaborado e partilhado. Tais representações sociais favorecem a identificação dos elementos que contribuem para a construção do saber fazer. ${ }^{23}$

A cosmovisão das parteiras sobre aspectos da atenção e da assistência ao parto permite a compreensão da complexidade do cuidado obstétrico, bem como a ressignificação dos saberes que orientam estas práticas, pois era extensivo ao recém-nascido, à família e ao espaço físico. O ofício praticado por estas mulheres provoca reflexão sobre limites e possibilidades do conhecimento científico e do saber popular. Neste estudo, infere-se que as evidências empíricas estão centradas expressivamente nos saberes populares relativos à assistência ao parto e aos seus mecanismos de inserção e aprendizado deste ofício.

Conhecimento e saber são conceitos distintos. O primeiro significa a constituição de um processo complexo de racionalização, identificação e classificação dos objetos, enquanto o saber designa o processo pelo qual o sujeito do conhecimento sofre uma modificação durante este aprendizado. ${ }^{24}$
Já o conhecimento científico é descrito como verdade absoluta, até que outro paradigma o venha sobrepujar - o que não se aplica ao saber popular, mais flexível e tolerante. O conhecimento tradicional diz respeito às informações acumuladas ao longo da vida em uma determinada comunidade, em relação às suas práticas, aos valores e à cultura, enfim, suas vivências e experiências. Estes conhecimentos não são permanentes e nem inabaláveis, pois são gerados, modificados e reformulados pela comunidade. O saber popular é transmitido de geração para geração, por meio de uma educação informal e baseada em observações e imitações. ${ }^{25}$

No âmbito das parteiras leigas, seus saberes foram modificados ao longo do tempo, por meio do crescimento da medicalização, que, aos poucos, foi transformando o ato fisiológico do parto em evento patológico, com a imposição da participação médica, em que a autonomia feminina sobre seu próprio corpo foi, aos poucos, substituída pelos biopoderes da ciência e suas tecnologias cada vez mais avançadas. ${ }^{2}$

Corroboram-se os aspectos normativos, éticos e epistêmicos da enfermagem obstétrica, que demonstram a necessidade da valorização do parto como momento único, respeitando todos seus significados, e devolvendo à mulher seu direito de ser mãe com humanidade e segurança.

As parteiras construíram, em suas interações e práticas sociais do cotidiano, um conjunto de representações do cuidado obstétrico que pode ser constituído como possibilidade futura de prática educativa, que envolva os profissionais da saúde, pela possibilidade do reconhecimento e da articulação dos diferentes modos de saber cuidar, criando sua própria identidade social. No entanto, a paixão e o compromisso com a assistência obstétrica elevam o custo emocional das parteiras. ${ }^{22}$

Aponta-se que existe uma lacuna na literatura relativa à pesquisas que tratam dos valores e das percepções descritos por meio das memórias das parteiras. Um limite do estudo foi a dificuldade de localizá-las, visto a invisibilidade destas mulheres nos órgãos públicos de saúde e o difícil acesso às suas moradias, uma vez que a maioria residia em zona rural.

\section{CONCLUSÃO}

O ofício das parteiras do semiárido brasileiro foi descrito como um dom, justificado pela facilidade em aplicar as técnicas e os rituais durante os partos realizados, de forma natural, intrínseca e transcendental. Alguns relatos descreveram seu 
surgimento de maneira autônoma ou transferidos por outras parteiras mais experientes, tendo como principal método de aprendizagem a observação.

As parteiras se inseriram no ofício motivadas pelo sentimento de altruísmo em um contexto histórico e social de ausência de acesso universal à saúde, localização geográfica rural e pouca disponibilidade de recursos humanos na saúde. No entanto, pela complexidade e pela necessidade de cuidados obstétricos exigidos no trabalho de parto, elas apresentaram uma cosmovisão ampliada de seu conceito.

Por meio da compreensão do contexto de inserção destas mulheres no ofício de partejar, pode-se inferir que ser uma parteira leiga em uma região brasileira de extrema pobreza e sem acesso universal aos serviços de saúde significa atuar de modo particular, por meio de seu ofício, dedicar-se e doar-se nos momentos mais necessários, prestando serviços sem retorno financeiro anunciado, com o objetivo de diminuir as morbimortalidades materna e infantil.

Esta atitude solidária levava ao aumento do poder pessoal das parteiras junto à comunidade, que necessitava de seus serviços e que, ao mesmo tempo, a legitimava socialmente, o que gerou sentimentos de tristeza pela extinção do ofício de partejar.

A história oral mostrou-se como método capaz de gerar dados como os demonstrados neste estudo, os quais aproximam-se de trajetórias e vivências que possibilitam compreender melhor um fenômeno neste caso, o ofício das parteiras.

\section{AGRADECIMENTOS}

À Fundação Cearense de Apoio ao Desenvolvimento Científico e Tecnológico (FUNCAP) pelo apoio financeiro. Ao Conselho Nacional de Desenvolvimento Científico e Tecnológico (CNPq) pelo apoio financeiro.

\section{REFERÊNCIAS}

1. Silva SP, Prates RC, Campelo BQ. Normal childbirth or cesarean? Factors affecting the choice of pregnancy. Rev Enferm UFSM [Internet]. 2014 Jan/Mar [cited 2017 Sep 27]; 4(1):1-9. Available from: https:// periodicos.ufsm.br/reufsm/article/view/8861

2. Barbosa CM, Dias MD, Silva MS, Caricio MR, Medeiros AP. Women and traditional midwives: care practices during the process of labor and birth at home. Rev Pesq: Cuid Fundam Online [Internet]. 2013 Jan/Mar [cited 2017 Sep 27]; 5(1):3206-20. Available from: http:/ / www.seer.unirio.br/index.php/ cuidadofundamental/article/viewFile/1893/pdf_678
3. Sanfelice CF, Shimo AK. Home childbirth: progress or retrocession? Rev Gaúcha Enferm. [Internet]. 2014 Mar [cited 2017 Sep 27]; 35(1):157-60. Available from: http://www.scielo.br/pdf/rgenf/v35n1/1983-1447rgenf-35-01-00157.pdf

4. Buainain AM, Garcia JR. Développement rural dans la région semi-aride du Brésil : transformations récentes, défis et perspectives. Confins [Internet]. 2013 [cited 2017 Sep 27];19. Available from: http://confins. revues.org/8633

5. Pimenta LF, Ressel LB, Stumm KE. The cultural construction of the birth process. J Res: Fundam Care Online [Internet]. 2013 Out/Dez [cited 2017 Sep 27]; 5(4):591-8. Available from: http://www.seer. unirio.br/index.php/cuidadofundamental/article/ view/2344/pdf_931

6. Matos GC, Escobal AP, Soares MC, Härter J, Gonzales RI. The historic route of childbirth car policies: an integrative review. J Nurs UFPE online. [Internet]. 2013 Mar [cited 2017 Sep 27]; 7(esp):870-8. Available from: http:/ / www.revista.ufpe.br/revistaenfermagem/ index.php/revista/article/view/3347/pdf_2229

7. Castro CM. [The meanings of planned home birth for women from the municipality of Sao Paulo]. Cad Saúde Colet [Internet]. 2015 [cited 2017 Sep 27]; 23(1):69-75. Available from: http://www.scielo.br/ pdf/cadsc/v23n1/1414-462X-cadsc-23-01-00069.pdf

8. Santos JB (coord.). Parteiras cearenses: História e memória do ofício de fazer o parto [Internet]. Fortaleza: Observatório de Recursos Humanos em Saúde Estação CETREDE/ UFC/UECE, 2007 [cited 2017 Sep 27]. Available from: http://www. observarh.org.br/observarh/repertorio/Repertorio_ ObservaRH/CETREDE/Parteiras_cearenses.pdf

9. Ferreira MM. História, tempo presente e história oral. Topoi (Rio J.). [Internet]. 2002 [cited 2017 Sep 27]; 3(5):314-32. Available from: http:// www.scielo. br/pdf/topoi/v3n5/2237-101X-topoi-3-05-00314.pdf

10. Meihy JC, Holanda F. História oral: como fazer e como pensar. 2. ed. São Paulo: Contexto; 2013.

11. Thompson P. A voz do passado: história oral. 3. ed. Rio de Janeiro: Paz e Terra, 1992.

12. Santana WJ. Is love a gift? A philosophical inquiry about givenness. Kriterion. [Internet]. 2016 Ago [cited 2017 Sep 27]; 57(134):441-54. Available from: http:/ / www.scielo.br/article_plus.php?pid=S0100-512X201 $6000200441 \&$ tlng $=$ en\&lng $=$ en

13. Hernandez JV, Wigström EM, Garate TO, Yzerbyt V, Goic CE. Variables related to satisfactory social identity and their differential effects on essentialism of ingroups and outgroups. Avanços Latin American Psychology [Internet]. 2015 [cited 2017 Sep 27]; 33(2):175. Available from: http:/ / go.galegroup.com/ ps $/$ anonymous? $\mathrm{p}=\mathrm{AONE} \& \mathrm{sw}=\mathrm{w} \& \mathrm{issn}=17944724 \&$ $\mathrm{v}=2.1 \& \mathrm{it}=\mathrm{r} \& \mathrm{id}=\mathrm{GALE} \% 7 C A 438950347 \& \mathrm{sid}=$ google Scholar\&linkaccess $=$ fulltext\&authCount $=1 \&$ isAnon ymousEntry=true 
14. Heimann C, Prado C, Moraes RR, Vidal GV, Liberal D, Oliveira GK, et al. Acquiring nursing knowledge through the constructivist method. Rev Esc Enferm USP [Internet]. 2013 [cited 2017 Sep 27]; 47(4):9971000. Available from: http://www.redalyc.org/ html/3610/361033327032/

15. Müller E, Rodrigues L, Pimentel C. [The taboo of childbirth Dilemmas and interdictions of a field under construction]. Civitas [Internet]. 2013 [cited 2017 Sep 27]; 15(2):272-93. Available from: http:/ / revistaseletronicas.pucrs.br/ojs/index.php/civitas/ article/view/17928/13393.Portuguese.

16. Feyer IS, Monticelli M, Volkmer C, Burigo RA. Brazilian scientific publications of obstetrical nurses on home delivery: Systematic literature review. Texto Contexto Enferm [Internet]. 2013 Jan/Mar [cited 2017 Sep 27]; 22(1):247-56. Available from: http:/ / www. scielo.br/pdf/tce/v22n1/30.pdf

17. Ferreira AG, Ribeiro MM, Dias LK, Ferreira JG, Ribeiro MA, Ximenes Neto FR. [Delivery and birth humanization: embracing the parturient from paulo freire's dialogic perspective]. Rev Enferm UFPE online [Internet]. 2013 Mai [cited 2017 Sep 27]; 7(5):1398-405. Available from: http://www.repositorio.ufc.br/ bitstream/riufc/5642/1/2013_art_agnferreira2.pdf. Portuguese.

18. Nazareth JV, de Souza KV, Beinner MA, Barra JS, Brüggemann OM, Pimenta AM. Special attention to women experiencing high-risk pregnancy: Delivery, care assistance and neonatal outcomes in two Brazilian maternity Ward. Midwifery. 2017; 53:42-8.

19. Guida NF, Pereira AL, Lima GP, Zveiter M, Araújo
CL, Moura MA. Compliance of nursing care practices with technical recommendations for normal birth. Rev Rene [Internet]. 2017 [cited 2017 Sep 27]; 18(4):543-50. Available from: http:/ / www.periodicos.ufc.br/rene/ article/view/20286/30818.Portuguese.

20. Wier J. Protecting the Public: An Investigation of Midwives Perceptions of Regulation and the Regulator. Midwifery. 2017;52:57-63.

21. Nascimento EG, Fortunato MM, Pereira AK, Miranda FN, Araújo JL, Pessoa GR. Limits and possibilities for effective humanized assistance in the perception of health professionals. J Nurs UFPE online [Internet]. 2015 [cited 2017 Sep 27]; 9(Suppl. 4):8002-11. Available from: http://www.periodicos.ufpe.br/revistas / revistaenfermagem/article/view/10553/11473

22. Howart AM, Scott KM, Swain NR. Skills-based childbirth preparation reduces stress for midwives. Midwifery. 2017; 50:235-8.

23. Carinhanha JI, Penna LH, Oliveira DC. [Social representations of families in vulnerable conditions: a literature review]. Rev Enferm UERJ [Internet]. 2014 Jul/ Ago [cited 2017 Sep 27]; 22(4):565-70. Available from: http:/ / www.facenf.uerj.br/v22n4/v22n4a21.pdf

24. Foucault M. Microfísica do poder. Organização e tradução de Roberto Machado. Rio de Janeiro: Edições Graal, 2009.

25. Silva SF, Melo Neto JF. Popular knowledge and scientific knowledge. Rev Temas em Educação [Internet]. 2015 Jul/Dez [cited 2017 Sep 27]; 24(2):13754. Available from: http:/ / periodicos.ufpb.br/index. php/rteo/article/view/25060/14567.
Correspondência: Samara Calixto Gomes

Rua Chico Inácio, 80

63540-000 - Juremal, Várzea Alegre, CE, Brasil

E-mail: samaracalixto@hotmail.com
Recebido: 17 de abril de 2017

Aprovado: 08 de novembro de 2017

This is an Open Access article distributed under the terms of the Creative Commons (CC BY). 